\title{
Facilitation of Fusarium graminearum Infection by 9-Lipoxygenases in Arabidopsis and Wheat
}

\author{
Vamsi J. Nalam, ${ }^{1,2}$ Syeda Alam, ${ }^{1}$ Jantana Keereetaweep, ${ }^{1}$ Barney Venables, ${ }^{1}$ Dehlia Burdan, ${ }^{3}$ \\ Hyeonju Lee, ${ }^{3}$ Harold N. Trick, ${ }^{3}$ Sujon Sarowar, ${ }^{1}$ Ragiba Makandar, ${ }^{1,4}$ and Jyoti Shah ${ }^{1}$ \\ ${ }^{1}$ Department of Biological Sciences, University of North Texas, Denton, TX 76203, U.S.A.; ${ }^{2}$ Department of Biology, Indiana \\ University-Purdue University, Fort Wayne, IN 46805, U.S.A.; ${ }^{3}$ Department of Plant Pathology, Kansas State University, \\ Manhattan, KS 66506, U.S.A.; ${ }^{4}$ Department of Plant Sciences, University of Hyderabad, Gachibowli, Hyderabad, India
}

Submitted 30 April 2015. Accepted 9 June 2015.

\begin{abstract}
Fusarium graminearum causes Fusarium head blight, an important disease of wheat. $F$. graminearum can also cause disease in Arabidopsis thaliana. Here, we show that the Arabidopsis LOX1 and LOX5 genes, which encode 9-lipoxygenases (9-LOXs), are targeted during this interaction to facilitate infection. $L O X 1$ and $L O X 5$ expression were upregulated in $F$. graminearuminoculated plants and loss of $L O X 1$ or $L O X 5$ function resulted in enhanced disease resistance in the corresponding mutant plants. The enhanced resistance to $F$. graminearum infection in the lox 1 and lox 5 mutants was accompanied by more robust induction of salicylic acid (SA) accumulation and signaling and attenuation of jasmonic acid (JA) signaling in response to infection. The lox1- and lox5-conferred resistance was diminished in plants expressing the SA-degrading salicylate hydroxylase or by the application of methyl-JA. Results presented here suggest that plant 9-LOXs are engaged during infection to control the balance between SA and JA signaling to facilitate infection. Furthermore, since silencing of TaLpx-1 encoding a 9-LOX with homology to LOX1 and LOX5, resulted in enhanced resistance against $F$. graminearum in wheat, we suggest that 9-LOXs have a conserved role as susceptibility factors in disease caused by this important fungus in Arabidopsis and wheat.
\end{abstract}

Fungi in genus Fusarium include several important phytopathogens. In wheat (Triticum aestivum) and barley (Hordeum vulgare), Fusarium head blight (FHB), which is an important disease of floral tissues, is caused by a complex of closely related Fusarium species. The principal causal agent for the disease in North America is Fusarium graminearum (Bai and Shaner 2004; McMullen et al. 1997a; Xu and Nicholson 2009). FHB epidemics in the past have resulted in losses ranging from $\$ 0.3$ to $\$ 3$ billion (Bai and Shaner 2004; Johnson et al. 2003). Infection initiates in the florets at anthesis from which the fungus spreads to additional spikelets causing them to bleach

Nucleotide sequence data is available under the following accession numbers: LOX1 (At1g55020), LOX5 (At3g22400), PR1 (At2g14610), ICS1 (At1g74710), PDF1.2 (At5g44420), EF1a (At5g60390), TaLpx-1 (GQ166692), F. graminearum nahG (XM_011322400.1).

Corresponding author: J. Shah; E-mail: Shah@unt.edu; Telephone: +1.940.565.3535; Fax: +1.940.565.4136.

*The $\boldsymbol{e}$-Xtra logo stands for "electronic extra" and indicates that six supplementary figures and one supplementary table are published online.

(c) 2015 The American Phytopathological Society and undergo necrosis (McMullen et al. 1997a). The infected tissues and the resulting grain contain mycotoxins that further limit acceptability of grain by the flour and malting industry and as a component in animal feed (Bai and Shaner 2004; McMullen et al. 1997b). Compounding the problem further is the nonavailability of wheat cultivars that are highly resistant to FHB. In addition, the use of fungicides for controlling FHB is constrained by cost, limited understanding of factors that affect disease, and practical difficulties with the efficient application of fungicide to floral tissues (McMullen et al. 1997b; Pirgozliev et al. 2003).

Limited information is available on the mechanisms employed by the host plant to control disease and how the fungus targets host physiology to promote infection. Although long considered a necrotrophic pathogen, on wheat, during early stages of infection, the fungus is restricted to extracellular spaces and fungal penetration of the host cells is not observed, suggesting the existence of a transient biotrophic phase in the infection cycle (Brown et al. 2010; Goswami and Kistler 2004). The subsequent switch to necrotrophy is associated with increased vigor of colonization and disease spread. Fungal infection is accompanied by changes in salicylic acid (SA) and jasmonic acid (JA) content and the activation of SA and JA signaling (Ding et al. 2011; Li and Yen 2008; Makandar et al. 2006, 2012; Pritsch et al. 2000; Yu and Muehlbauer 2001). Experiments with wheat plants expressing the bacterial nahG gene, which encodes a salicylate hydroxylase that degrades SA, confirmed that SA has an important role in controlling FHB severity (Makandar et al. 2012). Transgenic NahG plants exhibited heightened severity of FHB compared with the control nontransgenic wheat. The importance of SA signaling in limiting $F$. graminearum infection is further evident from the reduced severity of infection observed in wheat plants constitutively expressing the Arabidopsis NPR1 and PAD4 genes, which are important regulators of SA signaling and accumulation, respectively (Gao et al. 2013; Makandar et al. 2006, 2012, 2015). More recently, allelic variants of NPRl-like genes were shown to be associated with FHB resistance in winter wheat (Diethelm et al. 2014). In contrast to SA, JA was suggested to have dichotomous involvement in wheat $-F$. graminearum interaction, contributing to susceptibility during the early stages of infection via its antagonism of SA signaling and subsequently contributing to resistance during the later stages of infection (Makandar et al. 2012). Exposure of wheat plants to methyl-jasmonate (MeJA) vapors prior to fungal inoculation attenuated basal resistance (Makandar et al. 2012). However, when applied later during infection or when applied as repeated applications, MeJA limited FHB severity (Li and Yen 2008; Makandar et al. 2012). Several 
studies have shown that $F$. graminearum is capable of colonizing Arabidopsis leaves and floral tissues (Chen et al. 2006, 2009; Cuzick et al. 2008; Makandar et al. 2006, 2010, 2015; Savitch et al. 2007; Skadsen and Hohn 2004; Urban et al. 2002; Van Hemelrijck et al. 2006). Similar conclusions on the involvement of SA and JA signaling in plant interaction with $F$. graminearum have been derived from studies involving Arabidopsis in which SA was shown to promote resistance (Makandar et al. 2006, 2010; Savitch et al. 2007) and JA signaling was shown to attenuate the activation of SA signaling during the early phases of infection and, thus, facilitate infection (Makandar et al. 2010). However, later during infection, JA in conjunction with SA promoted resistance (Makandar et al. 2010). These studies have demonstrated that the Arabidopsis$F$. graminearum interaction is a good model pathosystem for characterizing the molecular and physiological basis of plant response to $F$. graminearum.

Oxylipins include an array of oxidized fatty acid-derived metabolites that have important roles in plant growth, development, and stress response. The first step in the synthesis of oxylipins involves oxygenation of polyunsaturated fatty acids to yield fatty acid hydroperoxides. This oxygenation of fatty acids can result from autooxidation or catalysis by enzymes like lipoxygenases (LOXs) and $\alpha$-dioxygenases (Feussner and Wasternack 2002). Based on whether they incorporate oxygen at the C-9 or C-13 position of the fatty acid to yield 9- or 13fatty acid hydroperoxides, LOXs can be broadly categorized as 9-LOXs and 13-LOXs, respectively. The fatty acid hydroperoxides can be further modified, either spontaneously or enzymatically, to yield an array of oxylipins (Feussner and Wasternack 2002; Mosblech et al. 2009). JA, which is one of the best-studied oxylipin with roles in plant development and stress response, is derived from the 13-LOX pathway (Browse 2009; Howe and Jander 2008; Wu and Baldwin 2010). 9-LOXs have also been linked to plant development, e.g., the development of lateral roots (Gao et al. 2008; Vellosillo et al. 2007). In addition, stress response in plants also engages the 9-LOX pathway. 9-LOX participation occurs in defense against bacterial and fungal pathogens as well as nematodes (Gao et al. 2008, 2009; Göbel et al. 2001; Hwang and Hwang 2010; López et al. 2011; Marmey et al. 2007; Montillet et al. 2013; Rustérucci et al. 1999; Vellosillo et al. 2007). 9-LOX-derived oxylipins have also been implicated in suppressing basal and inducible defense mechanisms in maize (Zea mays) (Constantino et al. 2013; Gao et al. 2007; Isakeit et al. 2007) and as signal molecules in cross-kingdom communication (Christensen and Kolomiets 2011).

Among the cereal crops, three LOX-encoding genes have been reported from barley ( $\operatorname{LoxA}, \operatorname{LoxB}$, and LoxC) (Doderer et al. 1992; van Mechelen et al. 1999) and three LOX-encoding loci ( $L p x-1, L p x-2$, and $L p x-3)$ have been reported from common wheat (Carrera et al. 2007; Hart and Langston 1977; Hessler et al. 2002). Based on protein sequence similarity, wheat $L p x-3$ corresponds to barley $\operatorname{LoxB}$, wheat $L p x-1$ (hereafter referred as TaLpx-1) is related to barley LoxA, which encodes a 9-LOX, and wheat $L p x$-2 corresponds to barley LoxC, which encodes a 13-LOX (Carrera et al. 2007; Doderer et al. 1992; Hessler et al. 2002; van Mechelen et al. 1999). Previously, LOXs have been linked with wheat defense against pests. For example, LOX activity is stimulated in wheat leaves treated with MeJA and fungal elicitors (Bohland et al. 1997; Mauch et al. 1997). The application of BTH (benzo $[1,2,3]$ thiadiazole-7-carbothioic acid $S$-methyl ester), a synthetic analog of SA that promotes resistance against several fungal pathogens (Görlach et al. 1996; Makandar et al. 2012), induced expression of WCI-2 (wheat chemically-induced 2), which encodes a putative LOX (Görlach et al. 1996). WCI-2 expression was also strongly upregulated during feeding by Hessian fly (Mayetiola destructor) larvae (Sardesai et al. 2005). In contrast, expression of a putative wheat $L O X$ was repressed in response to septoria leaf blotch caused by Mycosphaerella graminicola (Ray et al. 2003). Microarray studies also have indicated differential expression of wheat genes involved in oxylipin metabolism, including LOXs in wheat spikes challenged with $F$. graminearum (Kruger et al. 2002; Li and Yen 2008). However, the biological significance of altered expression or activity of these LOXs to the outcome of wheat interaction with pests is unclear.

Here, we show that, in both Arabidopsis and wheat, 9-LOXs have an important role in plant response to $F$. graminearum infection. $F$. graminearum disease severity was reduced in Arabidopsis and wheat plants in which expression of 9-LOXs was knocked down, thus confirming that these 9-LOXs facilitate $F$. graminearum infection in wild-type (WT) plants. Furthermore, the knockdown of LOX1 and LOX5 expression in Arabidopsis resulted in the attenuation of JA signaling and, simultaneously, more robust accumulation of SA and activation of SA signaling, which was required for the full extent of resistance in lox 1 and lox 5 mutant plants. Taken together with the observation that $L O X 1$ and $L O X 5$ expression was upregulated in $F$. graminearum-inoculated tissues, results presented here suggest that 9-LOX-derived oxylipins are engaged by the fungus to control balance between SA and JA signaling to facilitate infection.

\section{RESULTS}

\section{$L O X 1$ and $L O X 5$ expression is induced in response} to $F$. graminearum infection.

Expression of the 9-LOX-encoding Arabidopsis LOX1 (At1g55020) and LOX5 (At3g22400) genes (Bannenberg et al. 2009 ) was upregulated in response to $F$. graminearum infection (Fig. 1A). However, the temporal pattern of LOX1 and LOX5 induction in response to $F$. graminearum infection differed. While LOX5 expression was transiently induced, LOX1 expression showed a sustained induction response. The expression of LOX1 and LOX5 in response to $F$. graminearum infection was also examined in transgenic plants expressing a chimeric construct in which the expression of the $\beta$-glucuronidase (GUS) reporter was driven from either the LOX1 or LOX5 promoters (Vellosillo et al. 2007). In contrast to the temporally distinct pattern of LOXI and LOX5 induction in response to $F$. graminearum infection, histochemical analysis for GUS activity indicated an overlap in the spatial pattern of LOX 1 and LOX5 promoter activity in F. graminearuminoculated tissues (Supplementary Fig. S1). Strongest expression of the $L O X 1_{\mathrm{p}}$ :uidA and $L O X 5_{\mathrm{p}}$ :uidA reporters was observed in the minor veins of the $F$. graminearum-inoculated leaves.

The upregulation of LOX1 and LOX5 expression in $F$. graminearum-inoculated WT plants was accompanied by an increase in the content of the 9-LOX-derived oxylipin 9-HOD (9-hydroxyoctadecadienoic acid) (Fig. 1B). In contrast, this increase in 9-HOD was not observed in $F$. graminearuminoculated leaves of the loxl-1 lox5-1 double mutant, thus confirming that these 9-LOXs are required for $F$. graminearum infection-associated increase in 9-HOD content.

\section{Arabidopsis 9-LOXs promote severity}

\section{of $\boldsymbol{F}$. graminearum infection.}

The increase in Arabidopsis LOX1 and LOX5 expression and accumulation of 9-LOX-derived oxylipins in WT Arabidopsis could contribute to plant defense against $F$. graminearum. Alternatively, the expression of these genes might be targeted by the pathogen to facilitate infection. To discriminate between 
these possibilities, $F$. graminearum disease severity was compared between the WT Arabidopsis accession Columbia (Col0 ) and the lox 1-1 lox5-1 double mutant. As shown in Figure 2A, F. graminearum disease severity in the lox $1-1$ lox5-1 double mutant was significantly lower than in the WT plant. This reduction in disease severity correlated with lowered fungal growth in the lox1-1 lox5-1 mutant than the WT, which was monitored as the relative amount of $F$. graminearum DNA that accumulated in leaf tissues at 5 days postinoculation (dpi) (Fig. 2B). Pretreatment with 9-HOD or 9-HOT (9- hydroxyoctadecatrienoic acid) restored disease severity and fungal growth in the lox 1-1 lox 5-1 plants (Fig. 2A and B), thus confirming that one or more 9-LOX-derived oxylipins or the products thereof promotes F. graminearum infection in Arabidopsis.
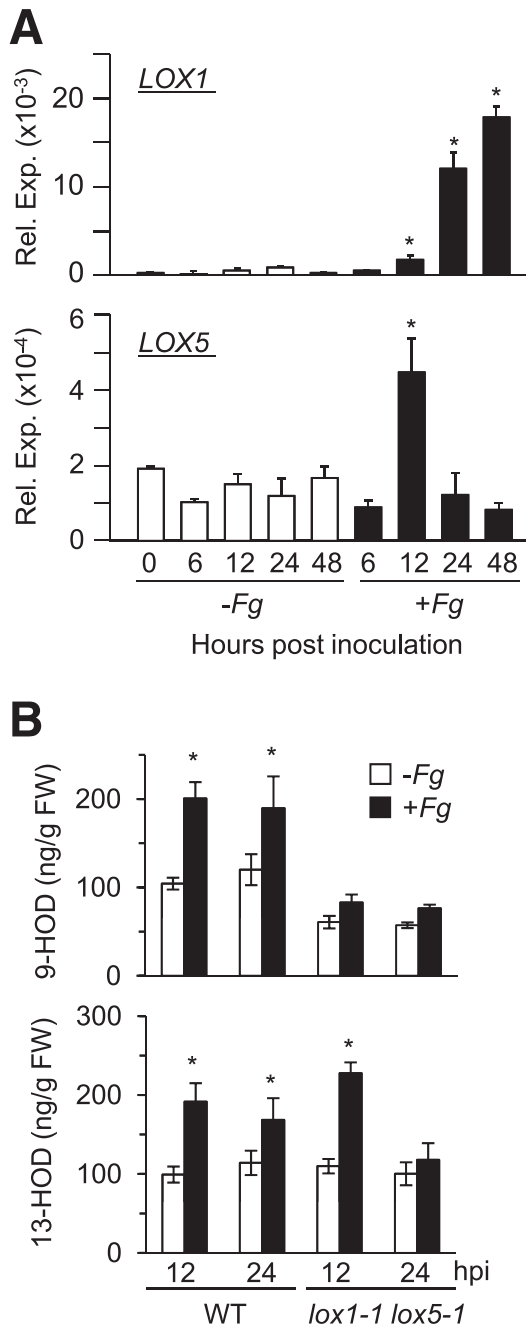

Fig. 1. LOX1 and LOX5 expression in response Fusarium graminearum infection. A, LOX1 and LOX5 expression in response F. graminearum inoculation. LOX1 (upper panel) and LOX5 (lower panel) expression in leaves of $F$. graminearum-inoculated $(+F g)$ and mock-inoculated $(-F g)$ wild-type (WT) plants. Quantitative real-time reverse-transcription-polymerase chain reaction was performed on RNA from leaves harvested at $0,6,12,24$, and $48 \mathrm{~h}$ postinoculation (hpi). The expression levels of LOX1 and LOX5 relative to expression levels of EF1 \pm \pm standard error at each time point is presented $(n=3)$. Asterisks above bars indicate values that are significantly different from the mock-inoculated for that time point $(P<0.05)$. B, 9-Hydroxyoctadecadienoic acid (9-HOD) and 13-HOD content in F. graminearum-inoculated Arabidopsis. Levels of 9- and 13-HOD were monitored in leaves of the WT and the lox $1-1$ lox5-1 double mutant at 12 and $24 \mathrm{hp}$ with $F$. graminearum $(+F g)$ and, as a control, in mock-inoculated $(-F g)$ plants. Error bars represent standard error. Asterisks above bars indicate values that are significantly different from the mock-inoculated for that time point $(P<0.05)$.
To determine the individual contribution of LOX1 and LOX5 in promoting $F$. graminearum infection, disease severity and fungal growth was monitored on the lox $1-1$ and lox5-1 single mutants. Disease severity and fungal growth were lower on the lox $1-1$ and lox5-1 mutants compared with the WT (Fig. 2A and B; Supplementary Fig. 2A and B). Similarly, disease severity
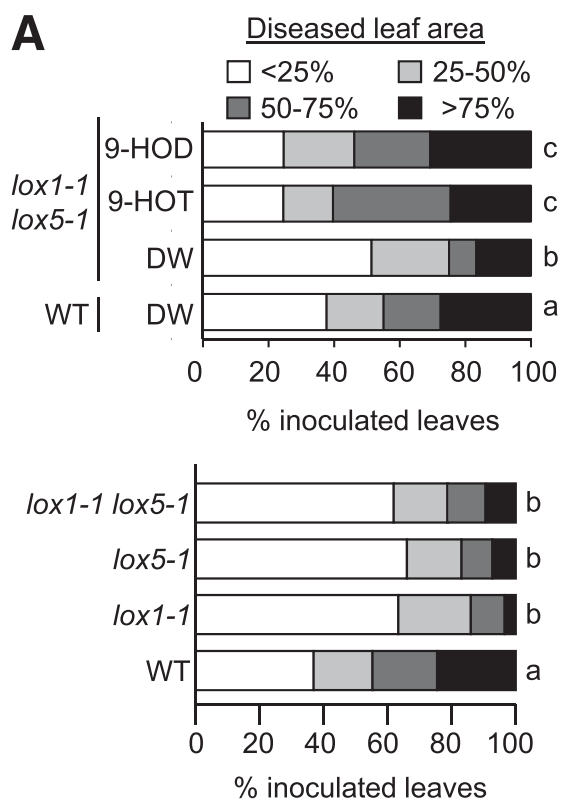

B
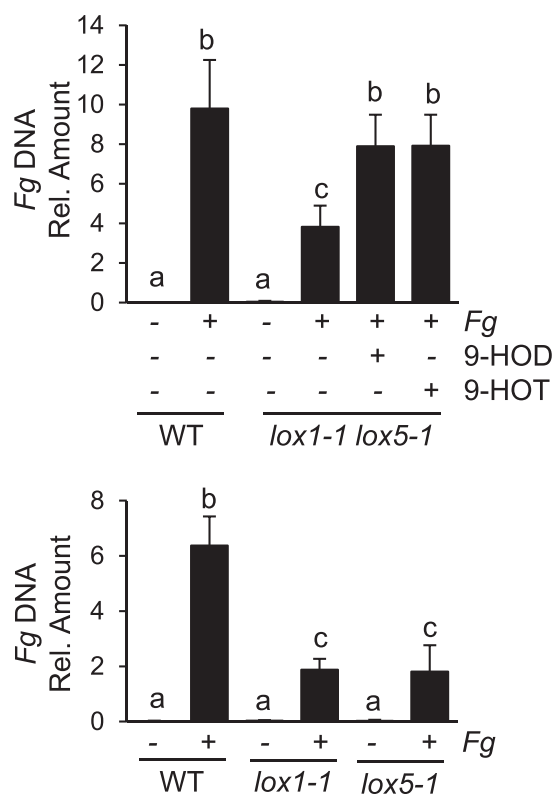

Fig. 2. Arabidopsis lox 1 and lox 5 mutants exhibit reduced severity of Fusarium graminearum infection. A, Upper panel, F. graminearum disease severity in leaves of the Arabidopsis lox1-1 lox5-1 double mutant plants infiltrated with distilled water (DW), and 9-hydroxyoctadecadienoic acid (9-HOD) and 9-hydroxyoctadecatrienoic acid (9-HOT) solutions $(1 \mu \mathrm{M})$ prepared in DW. Wild-type (WT) Col-0 plants infiltrated with DW provided the control. Lower panel, $F$. graminearum disease severity in leaves of Arabidopsis WT Col-0, lox1-1 and lox5-1 mutant, and lox1-1 lox5-1 double mutant plants. The percentage of inoculated leaves exhibiting necrosis covering $<25 \%, 25$ to $50 \%, 50$ to $75 \%$, and $>75 \%$ of the leaf area was determined for each genotype at 5 days postinoculation (dpi). Different letters next to the bars indicate values that are significantly different $(P<0.05)$ from each other. B, Quantitative polymerase chain reaction analysis for content of the $F$. graminearum nah $G$ gene relative to the Arabidopsis ACT8 gene \pm standard error $(n=3)$ in leaves of WT Col-0 and the lox $1-1$ lox5-1 double mutant at 5 dpi with $F$. graminearum $(F g)$. 
was lower on additional T-DNA knockdown alleles (lox $1-3$ and lox5-3) of LOX1 and LOX5. LOX1 and LOX5 expressed from the heterologous Cauliflower mosaic virus $35 S$ gene promoter restored $F$. graminearum disease severity in the loxl-1 and lox5-1 mutants, respectively, thus confirming the influence of these two 9-LOXs in facilitating $F$. graminearum infection in Arabidopsis. Since $F$. graminearum infection is a major disease of the spikes (floral tissues) of wheat and barley and F. graminearum can also infect Arabidopsis flowers, the effect of the lox 1-1, lox 1-3, lox5-1, and lox5-3 mutant alleles on $F$. graminearum disease severity was also evaluated in floral tissues, as previously described (Urban et al. 2002). Compared with the WT plants, the Fusarium-Arabidopsis disease (FAD) score was lower for the lox1-1, lox 1-3, lox5-1, and lox5-3 mutants (Table 1), thus indicating a higher level of resistance to $F$. graminearum in the floral tissues of Arabidopsis mutants lacking these 9-LOXs.

\section{Attenuation of JA signaling is associated with the enhanced disease resistance observed in the 9-LOX mutants.}

In addition to 9-LOX-derived 9-HOD, fungal infection of WT plants was also accompanied by an increase in the level of 13-HOD, a 13-LOX-derived oxylipin (Fig. 1B), thus suggesting increased 13-LOX activity. However, in comparison with the WT plant, in which 13-HOD levels were elevated at 12 and $24 \mathrm{~h}$ postinoculation (hpi), the accumulation of 13-HOD was transient in the fungus-inoculated loxl-1 lox5-1 mutant (Fig. 1B), thus suggesting that 9-LOXs, although not essential to the increase of 13-LOX-derived products, promoted the sustained activation of the 13-LOX pathway in $F$. graminearum-inoculated tissues. Since signaling mediated by JA, an important product of the 13-LOX pathway, has previously been shown to influence Arabidopsis interaction with $F$. graminearum, expression of the JA-responsive $P D F 1.2$ gene was compared between the WT and the lox 1-1 and lox5-1 mutants. As previously shown (Makandar et al. 2010), PDF1.2 expression in the WT plants showed a continual increase during the course of infection (Fig. 3A). In contrast, the induction of PDF1.2 was slower and significantly lower in the fungus-inoculated leaves of the lox $1-1$ and lox 5-1 plants. These results suggest that, in WT Arabidopsis, LOX1 and $L O X 5$ positively influence the robustness of JA signaling in response to $F$. graminearum infection.

The weaker induction of JA signaling in the 9-LOX mutants could result from the lowered severity of infection in these mutants. Alternatively, the heightened resistance against F. graminearum in the lox $1-1$ and lox5-1 mutants may result from the attenuation of JA signaling in these mutants. To further test these possibilities, WT and the loxl-1 and lox5-1 mutant plants were exposed to MeJA vapors, for a 24-h period immediately prior to inoculation with $F$. graminearum. As previously shown (Makandar et al. 2010), pretreatment with MeJA compared with ethanol, which was used as a solvent for MeJA, resulted in a significant increase in $F$. graminearum disease severity in WT plants (Fig. 3B). Similarly, MeJA treatment, as compared with ethanol treatment, attenuated the lox1-1- and

Table 1. Fusarium graminearum disease on Arabidopsis inflorescence

\begin{tabular}{lr}
\hline Genotype & FAD $^{\mathbf{a}}$ \\
\hline WT (Col-0) & $4.1 \pm 0.6$ \\
lox1-1 & $2.7 \pm 0.3$ \\
lox1-3 & $2.9 \pm 0.4$ \\
lox5-1 & $1.5 \pm 0.6$ \\
lox5-3 & $1.2 \pm 0.3$ \\
\hline${ }^{2}$ Fusarium-Arabidopsis disease (FAD) value was evaluated 7 days \\
postinoculation. This experiment was repeated twice with similar results.
\end{tabular}

lox5-1-conferred enhanced resistance against $F$. graminearum (Fig. 3B). Disease severity was comparable between the MeJAtreated WT and the MeJA-treated lox $1-1$ and lox5-1 mutants, thus indicating that activation of JA signaling prior to fungal inoculation breaks down the loxl-and lox5-determined resistance against $F$. graminearum. Taken together, these results suggest that the attenuation of JA signaling in response to fungal infection is associated with enhanced resistance against $F$. graminearum in the lox1 and lox5 mutants compared with the WT.

\section{lox1- and lox5-conferred enhanced resistance is coupled with robust activation of $\mathrm{SA}$ signaling.}

SA accumulation has an important function in limiting F. graminearum infection in Arabidopsis and wheat (Makandar et al. 2010, 2012, 2015). Previous studies have shown that enhancing sensitivity to SA by increasing expression of NPRI resulted in enhanced resistance against $F$. graminearum (Makandar et al. 2006, 2012). Here, we show that the temporal pattern of upregulation of $P R 1$ in response to the exogenous application of SA was comparable between the lox $1-1$ and lox 51 mutants and the WT plants (Supplementary Fig. S3). Furthermore, in comparison with the WT, pretreatment with SA
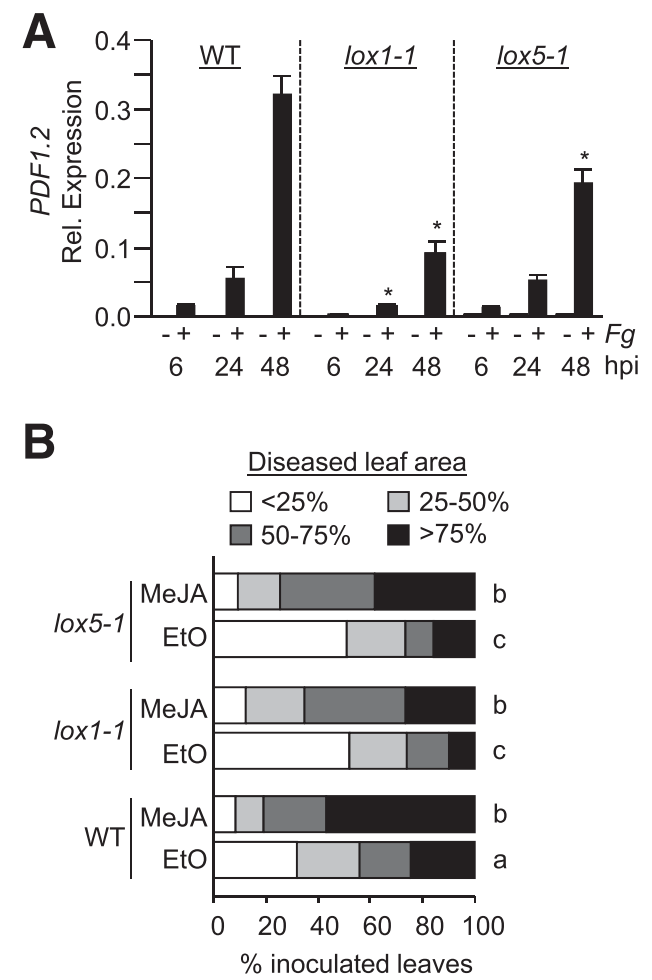

Fig. 3. Attenuation of jasmonic acid (JA) signaling is associated with the lox 1 - and lox5-conferred enhanced resistance against Fusarium graminearum. A, Expression of the jasmonate-responsive PDF1.2 gene in leaves of $F$. graminearum-inoculated $(+F g)$ Arabidopsis wild-type (WT) accession Col-0, lox 1-1, and lox5-1 plants. Quantitative real-time reverse-transcription-polymerase chain reaction was performed on RNA extracted from leaves of $F$. graminearum-inoculated plants harvested at 6, 24, and $48 \mathrm{~h}$ postinoculation (hpi). As a control, RNA was also extracted at the same time points from leaves of mock-inoculated plants $(-F g)$. The expression level of $P D F 1.2$ relative to expression level of $E F 1 \alpha \pm$ standard error at each time point is presented $(n=3)$. Asterisks indicate values that are significantly different $(P<0.05)$ from the WT for that time point and treatment. B, F. graminearum disease severity in leaves of WT accession Col-0, lox 1-1, and lox5-1 plants that were exposed to methyl-jasmonate (MeJA) vapors for a 24-h period immediately prior to inoculation with $F$. graminearum. Plants exposed to ethanol (EtO), which was used as a solvent for MeJA, provided the controls. Disease severity was recorded at 5 days postinoculation. Different letters next to the bars indicate values that are significantly different $(P<0.05)$ from each other. 
did not result in any significant increase in disease resistance in the lox $1-1$ and lox5-1 mutants (Fig. 4A), thus suggesting that SA-mediated defenses are likely fully engaged in the 9-LOX mutants. Although basal content of SA was comparable between the WT and the lox $1-1$ and lox 5-1 mutants in response to $F$. graminearum-inoculation, SA accumulation was higher in the lox $1-1$ and lox5-1 mutants than in the WT (Fig. 4B). Expression of the SA biosynthesis gene ICS1 and the SAinducible $P R 1$ gene were also higher in the $F$. graminearuminoculated lox $1-1$ and lox5-1 mutants compared with the WT plants (Fig. 4C; Supplementary Fig. S4). These results suggest that although the absence of 9-LOX function does not significantly affect basal SA content and signaling, in response to $F$. graminearum infection, the SA pathway is hyperactivated in the lox $1-1$ and lox5-1 mutants and is associated with

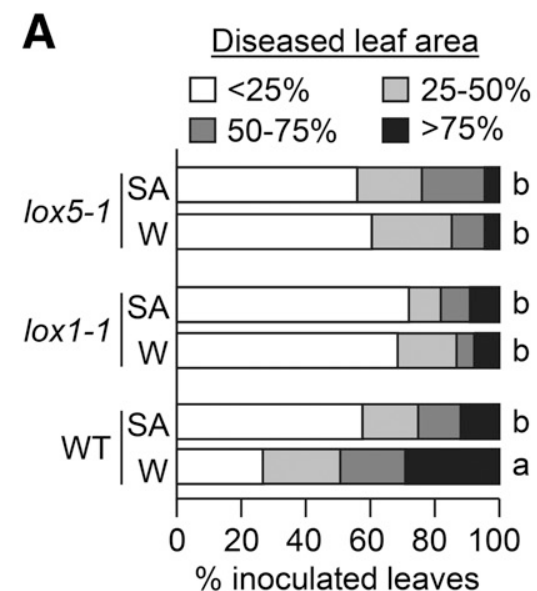

B
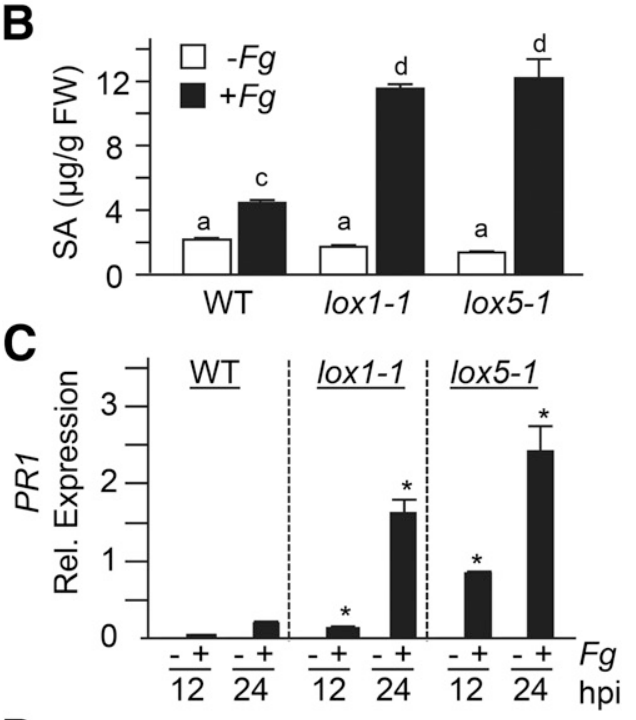

D

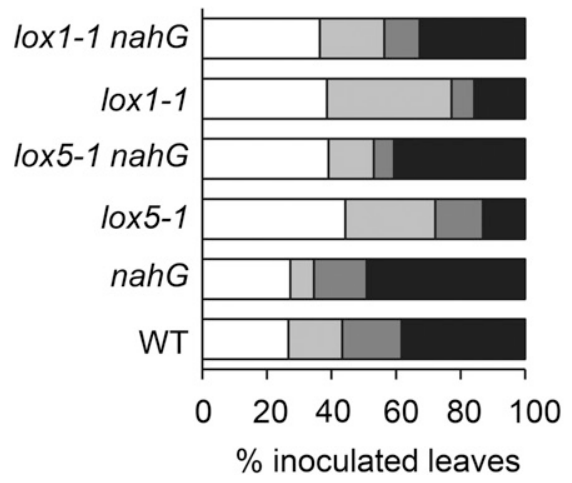

significantly greater accumulation of SA and stronger activation of SA signaling compared with the WT.

We postulated that if SA is critical for the lox 1-1- and lox 5-1conferred enhanced resistance to $F$. graminearum, then expression of the Pseudomonas putida nahG gene-encoded SA hydroxylase, which degrades SA, should diminish the lox 1 - and lox5-conferred resistance. Indeed, as shown in Figure 4D, the presence of nahG tempered the lox1-1- and lox5-1-conferred enhanced resistance, thus confirming the importance of SA to the lox 1-1- and lox5-1-conferred enhanced resistance against $F$. graminearum infection.

\section{Silencing of TaLpx-1 expression in wheat is accompanied by reduced severity of FHB disease.}

Wheat TaLpx-1 encodes a predicted 622-amino acid protein (molecular mass $=73.5 \mathrm{kDa}$ ) that exhibits 57 and $58 \%$ homology to Arabidopsis LOX1 and LOX5, respectively, in the region containing the lipoxygenase domain (PFAM00305) (Supplementary Fig. S5). The predicted coding sequence of TaLpx-1 also exhibits 95\% homology to the barley 9-LOX LoxA (data not shown). 9-LOXs catalyze the oxidation of polyunsaturated fatty acids to yield 9-hydroperoxy fatty acids, which can be further converted to the relatively more stable 9-hydroxy fatty acids. To determine if TaLpx-1 is a bona fide 9-LOX, the TaLpx-1 coding sequence was cloned from the wheat $\mathrm{cv}$. Bobwhite, the corresponding protein was expressed in Escherichia coli, and its ability to utilize linoleic acid as a substrate to yield 9-HOD was determined. The Arabidopsis LOX1 provided the positive control for this assay. LOX1 and TaLpx-1 activity on linoleic acid resulted in the accumulation of 9-HOD (Fig. 5), thus confirming that TaLpx-1, like LOX1, contains 9-LOX activity. TaLpx-1 action also resulted in the accumulation of 13-HOD. However, the 13-HOD produced was only $5 \%$ of the amount of 9 -HOD produced by TaLpx-1, suggesting that TaLpx-1 is a 9-LOX with minor 13-LOX activity. Since TaLpx-1 is expressed in wheat spikes (Supplementary Fig. S6), we predicted that, like LOX1 and LOX5 in Arabidopsis, TaLpx-1 is involved in wheat $-F$. graminearum interaction. To test this hypothesis, wheat plants (cv. Bobwhite) were generated in which RNA interference (RNAi) technology was utilized to silence expression of TaLpx-1 (discussed below). Compared with the nontransgenic parental cv. Bobwhite, expression of TaLpx-1 was knocked down in transgenic lines

$\leftarrow$

Fig. 4. $\operatorname{lox} 1$ and lox 5 mutants exhibit stronger accumulation of salicylic acid (SA) in response to Fusarium graminearum infection. A, F. graminearum disease severity in Arabidopsis wild-type (WT) accession Col-0 and the lox $1-1$ and lox5-1 mutant plants that were treated with a $200-\mu \mathrm{M}$ solution of SA or, as control, with water (W) $24 \mathrm{~h}$ prior to inoculation with F. graminearum. Disease severity was recorded at 5 days postinoculation (dpi). Different letters next to the bars indicate values that are significantly different $(P<0.05)$ from each other. B, SA content \pm standard error in leaves of Arabidopsis WT Col-0, lox 1-1 and lox5-1 plants that were inoculated with $F$. graminearum $(+F g)$, or as control in mock-inoculated $(-F g)$ plants, $24 \mathrm{~h}$ postinoculation (hpi). Different letters above the bars indicate values that are significantly different $(P<0.05)$ from each other $(n=3)$. FW, fresh weight of leaf tissue. C, Quantitative real-time polymerase chain reaction analysis of PRI expression in leaves of $F$. graminearum-inoculated and mock-inoculated Arabidopsis wild-type (WT) accession Col-0, lox 1-1 and lox5-1 plants at 12 and 24 hpi. Level of PR1 transcript relative to that of $E F 1 \alpha \pm$ standard error at each time point is presented $(n=3)$. Asterisks represent values that are significantly different $(P<0.05)$ from the corresponding WT for that treatment and time point. D, $F$. graminearum disease severity in Arabidopsis WT accession Col-0, the lox 1-1, lox5-1, lox1-1 nahG, and lox5-1 nahG plants. Disease severity was recorded at 5 dpi. Disease severity in the lox $1-1$ nahG and lox5-1 nahG plants is significantly higher $(P<0.05)$ than that in the lox $1-1$ and lox 5-1 mutants, respectively. 
1097B, 1073A, and 1218A (Fig. 6A). Spikes of these TaLpx-1silenced lines were challenged with $F$. graminearum to determine if reduction of TaLpx-1 expression had any impact on $F$. graminearum disease severity. $F$. graminearum disease severity was monitored over a 21-day period, as previously described (Makandar et al. 2006, 2012). Compared with the nontransgenic plants, disease severity, represented as percentage of infected spikelets, was significantly lower in all three TaLpx-1-silenced lines (Fig. 6B), thus confirming that reduction in TaLpx-1 expression is accompanied by enhanced resistance to $F$. graminearum in wheat. These results strongly suggest conservation in the involvement of 9-LOXs in Arabidopsis and wheat susceptibility to F. graminearum.

\section{DISCUSSION}

9-LOXs catalyze the synthesis of 9-hydroperoxy fatty acids, which serve as precursors for a variety of oxylipins and products thereof. Our results indicate that 9-LOXs in Arabidopsis and wheat facilitate infection by $F$. graminearum, an important pathogen of small grain cereals. We have shown that T-DNA insertion-mediated knockdown of LOX1 and LOX5, which encode the two 9-LOXs in Arabidopsis (Bannenberg et al. 2009), resulted in reduced severity of disease caused by $F$. graminearum (Fig. 2A and B). Similarly, RNAi-mediated knockdown of TaLpx-1, which encodes a protein with homology to the Arabidopsis LOX1 and LOX5 proteins and has 9-LOX activity (Fig. 5B), was accompanied by reduced severity of FHB in wheat (Fig. 6B). These results indicate that one or more 9-LOX products or factors dependent on them is a susceptibility factor that promotes $F$. graminearum infection. Indeed, pretreatment with 9-HOD or 9-HOT attenuated the enhanced resistance phenotype conferred by 9-LOX deficiency in the lox1-1 lox5-1 mutant plant (Fig. 2A and B). Expression of both LOX1 and LOX5 in Arabidopsis is upregulated in response to $F$. graminearum infection (Fig. 1A), thus suggesting that $F$. graminearum might target expression of these 9-LOX genes to facilitate infection. Similarly, upregulation of LOX5 expression and accumulation of 9-LOX products in roots promotes colonization of Arabidopsis by the green peach aphid (Nalam et al. 2012, 2013), and in maize, expression of the 9-LOX-encoding $\mathrm{ZmLOX3}$ gene that facilitates infection by F. verticillioides is upregulated in the fungus-inoculated kernel (Gao et al. 2007; Wilson et al. 2001). The contribution of lipids to wheat susceptibility to $F$. graminearum is further supported by the fact that one of the pathogenicity factors secreted by F. graminearum is the FGL1 lipase (Blümke et al. 2014; Voigt et al. 2005). The fgll mutant fungus, although capable of infecting wheat, was unable to spread from the inoculated site, suggesting the involvement of FGLl in promoting fungal spread through the host. It is plausible that a FGL1-released fatty acid functions as the substrate for TaLpx1 in wheat.

The comparable level of resistance against $F$. graminearum observed in the Arabidopsis lox1-1 lox5-1 double mutant and the single mutant plants (Fig. 2B) leads us to suggest that these genes have a common role in Arabidopsis interaction with $F$. graminearum and together contribute to a minimum threshold level of 9-LOX activity that is involved in facilitating
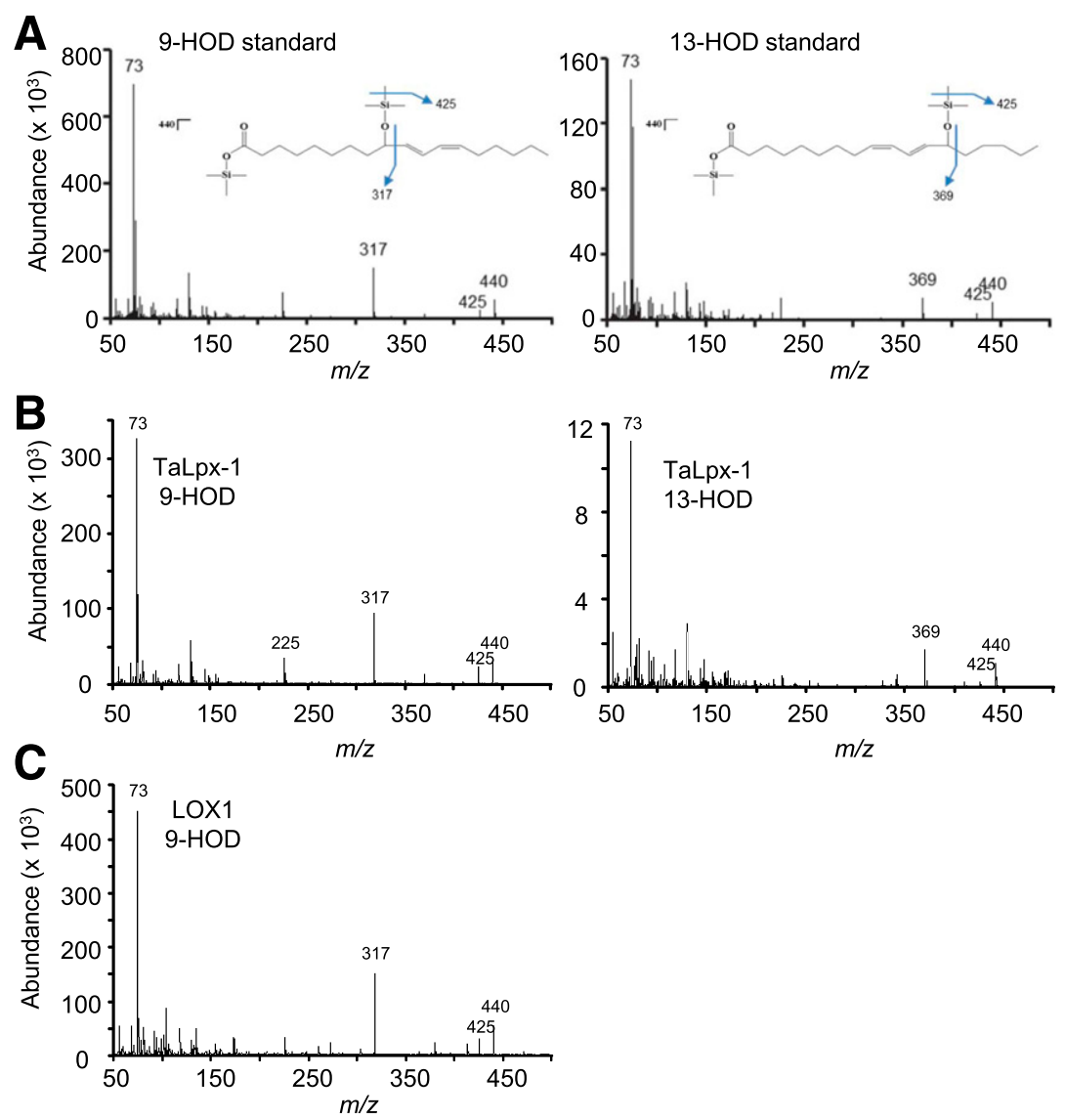

Fig. 5. Positional specificity of lipoxygenase activity of TaLpx-1. Gas chromatography-mass spectrometry analysis of trimethylsilyl derivatives of 9-HOD (9hydroxyoctadecadienoic acid) and 13-HOD standard and products of TaLpx-1 and Arabidopsis LOX1 action on linoleic acid. The diagnostic ions for 9-HOD and 13-HOD are $\mathrm{m} / \mathrm{z} 317$ and 369, respectively. A, Fragmentation pattern for 9-HOD and 13-HOD standards. Insets indicate the key diagnostic ions for each species. B, Fragmentation pattern of 9-HOD and 13-HOD produced by recombinant TaLpx-1. C, Fragmentation pattern of 9-HOD produced by recombinant Arabidopsis LOX1. 
F. graminearum infection. When either of these gene functions is knocked down, there is insufficient accumulation of one or more 9-LOX-dependent factors that promote $F$. graminearum infection. The strong expression of both these genes in the vasculature indicates an overlap in their major expression domain in response to $F$. graminearum infection. LOX5, which reaches peak expression levels by $12 \mathrm{hpi}$, might contribute early during the infection process compared with $L O X 1$, which is induced later, but shows a more sustained induction during the course of the experiment (Fig. 1A). Furthermore, since the LOX1 protein localizes to chloroplasts, as compared with the extraplastidic location of LOX5 (Nalam et al. 2012), we suggest that the intracellular origin of these 9-LOX products is not critical for facilitating $F$. graminearum infection. This is in striking contrast to the role of 9-LOX function in Arabidopsis interaction with the green peach aphid, in which only LOX5 is involved in facilitating insect infestation (Nalam et al. 2012).

Previously, it was shown that Arabidopsis and wheat accumulate elevated levels of SA in response to $F$. graminearum infection and that SA signaling is critical for limiting F. graminearum infection in these plants (Gao et al. 2013; Makandar et al. 2006, 2010, 2012, 2015; Savitch et al. 2007). In contrast, JA was shown to have a dichotomous role in Arabidopsis and wheat interaction with $F$. graminearum (Makandar et al. 2010, 2012). By constraining the activation of SA signaling during the early stages of infection, JA functioned as a susceptibility factor. However, later during infection, JA and SA had an additive effect on defense against $F$. graminearum (Makandar et al. 2010, 2012). Similar antagonistic and synergistic interactions between SA and JA have been reported by others with other pathosystems (Kunkel and Brooks 2002; Mur et al. 2006). The basal content of SA and level of $P R I$ transcript were comparable in WT and lox 1 and lox5 mutant plants (Fig. 4B and C), thus indicating that LOXI and LOX5 do not
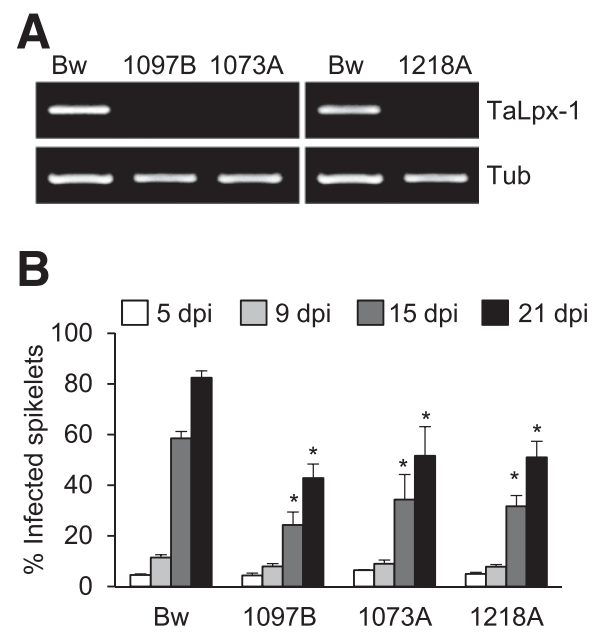

Fig. 6. Fusarium head blight (FHB) resistance is enhanced in wheat plants silenced for expression of TaLpx-1. A, Reverse-transcription-polymerase chain reaction (RT-PCR) analysis showing knockdown of TaLpx-1 expression in the wheat RNA-interference (RNAi) lines 1097B, 1073A, and 1218A. Nontransgenic cv. Bobwhite (Bw) plants provided the control for TaLpx-1 expression. Expression of wheat tubulin $(T u b)$ gene provided the control for RT-PCR. B, FHB severity in TaLpx-1 RNAi lines. FHB disease rating was monitored in $\mathrm{Bw}$ and the three independently derived TaLpx-1 RNAi lines 1097B, 1073A, and 1218A, in which TaLpx-1 expression was attenuated. Disease incidence was recorded as the percentage of infected spikelets in each spike at $5,9,15$, and 21 days postinoculation (dpi) with $F$. graminearum spores. Bars represent means \pm standard error. Asterisks identify values that are significantly different $(P<0.05)$ from the nontransgenic $\mathrm{Bw}$ for that time point. $\mathrm{Bw}(n=26) ; 1097 \mathrm{~B}(n=18) ; 1073 \mathrm{~A}$ $(n=5) ; 1218$ A $(n=8)$. influence basal SA accumulation and signaling. However, the F. graminearum-inoculated lox 1 and lox 5 plants contained significantly higher levels of SA than $F$. graminearum-inoculated WT plants (Fig. 4B). The higher content of SA correlated with the stronger expression of $P R I$ in $F$. graminearum-inoculated lox 1 and lox5 mutants compared with the WT plant (Fig. 4C). Above all, expression of the nahG gene attenuated loxl-1- and lox5-1conferred resistance (Fig. 4D), thus indicating that, in the WT plants, these 9-LOXs limit the accumulation of SA and the strength of downstream defense signaling in response to fungal infection. The stronger expression of ICSI in the fungusinoculated lox 1 and lox 5 mutants compared with the WT plant suggests that this robust increase in SA in the lox 1 and lox5 mutant plants is likely due to increased synthesis of SA in response to fungal infection. However, it is equally possible that, in the $F$. graminearum-inoculated lox 1 and lox 5 mutants, as compared with the WT plant, SA turnover is lower. 9-LOXsynthesized lipids can influence fungal physiology, including toxin production and development (Brodhagen and Keller 2006). Similarly, it is plausible that plant 9-LOX-synthesized oxylipins influence production of factors by $F$. graminearum that either limit SA production, promote SA turnover in the infected plant tissue, or both. Indeed, pathogenic fungi are known to secrete enzymes, like chorismate mutase, that limit SA production in the host and, thus, facilitate infection (Djamei et al. 2011). Furthermore, the $F$. graminearum genome contains a homolog of the bacterial $n a h G$ gene, which is predicted to encode a secreted salicylate hydroxylase that could potentially promote SA turnover in infected tissue (Brown et al. 2012).

In contrast to the robust induction of SA signaling in response to $F$. graminearum infection, the induction of PDF1.2, a marker gene for JA signaling activation, was attenuated in the fungus-infected lox 1 and lox5 mutants (Fig. 3A), thus suggesting that, in the WT plants, 9-LOX products are required for the full extent of JA signaling. A sustained accumulation of 13HOD that is observed in $F$. graminearum-inoculated WT plants was not observed in the lox $1-1$ and lox5-1 mutants (Fig. 1C), thus, further suggesting that in F. graminearum-infected plants, 9-LOX activity promotes activity of the 13-LOX pathway. A weak JA response could account for the stronger accumulation of SA in the 9-LOX mutants. JA signaling is known to antagonize the activation of SA signaling during plant defense (Pieterse et al. 2009), and previous studies have shown that JA signaling impairs the induction of SA accumulation and signaling in $F$. graminearum-infected Arabidopsis and wheat (Makandar et al. 2010, 2012). Alternatively, in the loxl and lox5 mutants, the stronger activation of SA signaling could adversely impact activation of JA signaling. It is also possible that the weaker induction of the JA pathway in $F$. graminearuminoculated lox $1-1$ and lox5-1 is due to lowered fungal growth and spread on this mutant and not due to a more direct impact of 9-LOX products on JA signaling.

The influence of plant 9-LOXs on control of SA and JA signaling has also been reported in other pathosystems. For example, in maize, a $Z m L O X 3$-dependent mechanism that promotes resistance against the root knot nematode Meloidogyne incognita limits biosynthesis of both SA and JA (Gao et al. 2008). In case of Arabidopsis interaction with the bacterial pathogen Pseudomonas syringae, 9-LOX-synthesized oxylipins are required for controlling infection by suppressing JA signaling and simultaneously promoting SA signaling (Vicente et al. 2012). These physiological changes are in contrast to the results presented here showing the promotion of JA signaling and the attenuation of SA signaling by $L O X 1$ - and LOX5-dependent mechanisms in $F$. graminearum-infected Arabidopsis. Thus, depending on the host and pathogen, 9-LOXs have different effects on modulating SA and JA signaling, 
suggesting that other factors associated with microbial infection influence the impact of 9-LOXs on host hormonal physiology.

In summary, this study has revealed that the ArabidopsisF. graminearum pathosystem, which previously has been used to study plant defense against $F$. graminearum, also provides a good model system for the identification of factors that contribute to host susceptibility to $F$. graminearum, an agronomically important pathogen. Genetic studies indicate that Arabidopsis 9-LOXs facilitate $F$. graminearum infection. These 9-LOXs control the balance between SA and JA signaling in $F$. graminearum-infected plants. The reduced FHB severity observed in TaLpx-1-silenced wheat lines reveals conservation in the engagement of 9-LOX-dependent mechanisms for facilitating $F$. graminearum infection in Arabidopsis and wheat.

\section{MATERIALS AND METHODS}

\section{Plant material and growth conditions.}

Arabidopsis was cultivated in a growth room set at $22^{\circ} \mathrm{C}$ under a 14-h light $\left(100 \mu \mathrm{E} \mathrm{m}^{-2} \mathrm{~s}^{-1}\right)$ and 10 -h dark regime. Approximately 4-week-old plants were used for all experiments. The lox1-1 (SALK_059431), lox1-3 (SALK_012188), lox5-1 (SALK_044826), and lox5-3 (SALK_050933) T-DNA insertion alleles, which are in Arabidopsis accession Col-0, have been previously described (Nalam et al. 2012). The $L O X 1_{\mathrm{p}}: G U S$ and $L O X 5_{\mathrm{p}}: G U S$ lines in which the GUS reporter is expressed from the $L O X 1$ and the $L O X 5$ gene promoters were previously described (Vellosillo et al. 2007). The loxl-1 nahG and lox5-1 nahG lines were generated by transforming the loxl-1 and lox5-1 mutant plants with a T-DNA construct containing the Pseudomonas putida nahG gene (Shah et al. 1999). Wheat was grown in a greenhouse with a $21^{\circ} \mathrm{C}$ day and $18^{\circ} \mathrm{C}$ night temperature regime. Three plants were grown per gallon-capacity pot. The compost-and peat-based Fafard \#2 soil mix (Sungro) was used for cultivating Arabidopsis and wheat. Prior to use, it was sterilized by autoclaving.

\section{Fungal cultivation and plant infections.}

$F$. graminearum isolate Z-3639 was cultured on half-strength potato dextrose agar (Difco Laboratories) at $22^{\circ} \mathrm{C}$. Fungal inoculations of Arabidopsis leaves were carried out as previously described (Makandar et al. 2010). The fungal suspension was infiltrated into the abaxial surface of four to five leaves per Arabidopsis plant with a needleless syringe. The inoculated plants were left covered with a clear plastic dome in the growth room for 2 days, after which the dome was removed and the infection was allowed to proceed for 3 additional days at ambient humidity. The percentage of inoculated leaves exhibiting chlorosis covering $<25 \%$ (category I), 25 to $50 \%$ (category II), 50 to $75 \%$ (category III), and $>75 \%$ (category IV) of the leaf area were determined for each genotype, as previously described (Makandar et al. 2010). A minimum of 60 leaves of each genotype were analyzed for each experiment. Disease severity among different genotypes and treatments was compared by single factor analysis of variance (ANOVA) $(P<0.05)$ (SAS v5.1). Inoculations of Arabidopsis inflorescence with F. graminearum spores and disease rating expressed as the FAD score were conducted as previously described (Makandar et al. 2010; Urban et al. 2002).

Inoculation of wheat spikes with $F$. graminearum spore suspension have been previously described (Makandar et al. 2006, 2012). Disease was evaluated as percentage of diseased spikelets over a 21-day period. The significance of the data was tested by $t$ test and ANOVA, using the GLM procedure available in Minitab version 15 (Minitab Inc.).
GUS staining.

Staining for GUS activity in leaves of the $L O X 1_{\mathrm{p}}: U i d A$ and LOX5 :UidA lines was performed as previously described (Malamy and Benfey 1997).

\section{RNA and DNA isolation and analysis.}

DNA and RNA extraction from plant tissues (Arabidopsis leaves and wheat spikelets) and cDNA synthesis were performed as previously described Makandar et al. 2010, 2012; Nalam et al. 2012). All RNA samples were treated with RNAsefree DNAse to destroy contaminating DNA. For each time point and treatment, RNA was collected from three biological replicates, each consisting of leaves/spikes pooled from four plants. The AtRTPrimer database (Han and Kim 2006) was used to design gene-specific primers (Supplementary Table S1) for reverse transcription polymerase chain reaction (RT-PCR) and quantitative real time PCR. PCR conditions were as follows: $95^{\circ} \mathrm{C}$ for $5 \mathrm{~min}$, followed by 25 cycles of $95^{\circ} \mathrm{C}$ for $30 \mathrm{~s}, 58^{\circ} \mathrm{C}$ for $45 \mathrm{~s}$, and $72^{\circ} \mathrm{C}$ for $45 \mathrm{~s}$, followed by a final extension step of $72^{\circ} \mathrm{C}$ for $5 \mathrm{~min}$. Quantitative (q)PCR was performed with Sybr green PCR master mix (Applied Biosystems) on an Eco Illumina system, using the following amplification protocol: $10 \mathrm{~min}$ at $95^{\circ} \mathrm{C}$ for polymerase activation and denaturation of nucleic acids, followed by 40 cycles of $95^{\circ} \mathrm{C}$ for $10 \mathrm{~s}, 58^{\circ} \mathrm{C}$ for $30 \mathrm{~s}$, and $72^{\circ} \mathrm{C}$ for $30 \mathrm{~s}$. This was followed by a product melt to confirm a single PCR product. The level of gene expression was normalized to that of $E F 1 \alpha$ by subtracting the cycle threshold $\left(\mathrm{C}_{\mathrm{T}}\right)$ value of EF1 $\alpha$ from the $\mathrm{C}_{\mathrm{T}}$ value of the gene of interest. The $\Delta \Delta \mathrm{C}_{\mathrm{T}}$ method (Livak and Schmittgen 2001) was used to calculate relative fold changes.

qPCR was used to detect the presence of fungus in plant tissue. DNA from fungus-infected and mock-inoculated leaves was used for qPCR analysis. Primers designed to the $F$. graminearum NahG gene were used to monitor amount of fungus relative to Arabidopsis EF1 $\alpha$.

\section{Chemical and hormone treatment.}

A $200-\mu \mathrm{M}$ working solution of MeJA (Sigma Aldrich) was prepared in $0.1 \%$ ethanol. Cotton plugs soaked with $1 \mathrm{ml}$ of the MeJA solution or, as control, with $0.1 \%$ ethanol were placed in a petri plate at the center of an airtight plexiglass chamber (48liter volume) in which the plants to be treated were placed. The plants were left in the chamber exposed to MeJA vapors or, as control, to $0.1 \%$ ethanol for $24 \mathrm{~h}$, after which they were removed and inoculated with the fungus.

SA treatment of Arabidopsis was initiated by irrigating and spraying plants to run-off with a $200-\mu \mathrm{M}$ solution of sodium salicylate (Sigma Aldrich) in water. Plants were inoculated with $F$. graminearum $24 \mathrm{~h}$ later, and disease severity was evaluated 5 dpi with the fungus. Plants irrigated and sprayed with water provided the controls.

Treatment of plants with 9-HOD and 9-HOT was initiated by infiltrating $1-\mu \mathrm{M}$ solutions prepared in distilled water into the abaxial surface of Arabidopsis leaves with a needleless syringe $3 \mathrm{~h}$ prior to fungal inoculation. Leaves infiltrated with distilled water provided the controls.

\section{SA quantification.}

Quantification of SA content in Arabidopsis leaves was done using a modified biosensor strain of Acinetobacter sp. strain ADP1 (Huang et al. 2005, 2006).

\section{Isolation and cloning of putative wheat lipoxygenases.}

The isolation and cloning of TaLpx-1 was carried out as previously described (Feng et al. 2010). Briefly, wheat expressed sequence tags (EST) identified as putative LOXs belonging to TaLpx-1 were used as queries to search the wheat 
genome database Dana-Farber Cancer Institute Wheat Gene Index. This resulted in the identification of a tentative contig representing the TaLpx-1 locus. By comparing the sequences of EST covering the tentative contig, primers were designed to amplify putative full-length TaLpx-1 cDNA from wheat tissue. cDNA generated from total RNA extracted from roots of germinating seedlings of the wheat cv. Bobwhite was used as the template. The PCR product $(1.9 \mathrm{~kb})$ was cloned and was sequenced for confirmation. The cloned product contained a fully functional lipoxygenase domain (PFAM00305) and corresponded to GenBank accession GQ166692, which was previously identified by Feng et al. (2010) as Triticum aestivum LOX1 (TaLOX1). However, the primers used in this study did not result in the cloning of the PLAT/LH2 domain that was identified by Feng et al. (2010) as being part of the TaLOX1.

\section{LOX reaction and identification of LOX products.}

The full-length coding region of AtLOXI and TaLpx-1 were cloned in the pET28c vector (Novagen). BL21 (DE3) cells (Invitrogen) were used to express the recombinant proteins. To induce expression of the recombinant gene, the bacterial cultures were treated for $5 \mathrm{~h}$ with isopropyl $\beta$-D-1thiogalactopyranoside $(1 \mathrm{mM})$, after which the cells were harvested in lysis buffer $\left(50 \mathrm{mM} \mathrm{NaH} \mathrm{PO}_{4}, 300 \mathrm{mM} \mathrm{NaCl}\right.$, $10 \mathrm{mM}$ imidazole, $\mathrm{pH} 8.0$, adjusted with $\mathrm{NaOH}$ ) and were lysed by sonication. The soluble protein obtained after pelleting cell debri at $10,000 \times g$ for $10 \mathrm{~min}$ was incubated with $2 \mathrm{mg}$ of $18: 2$ (linoleic acid) or 18:3 (linolenic acid) (Cayman Chemicals) at room temperature for $1 \mathrm{~h}$.

The extraction and identification of oxylipins was carried out as previously described (Keereetaweep et al. 2013). Lipids were extracted, were reduced with $\mathrm{NaBH}_{4}$, and were resuspended in methanol. The separation of oxylipins was performed on an Agilent 1100 high-performance liquid chromatography (HPLC) system. The UV diode array detector was set at $234 \mathrm{~nm}$ to monitor the conjugated diene system. An EC 250/2 nucleosil $120-5$ C18 column $(250 \times 25 \mathrm{~mm}, 5 \mu \mathrm{m}$ particle size, ID $2 \mathrm{~mm})$ (Macherey and Nagel) was used for reverse phase HPLC with a binary gradient system (solvent A, methanol/water/acetic acid [80:20:0.1, vol/vol/vol]; solvent $\mathrm{B}$, methanol/acetic acid [100: $0.1, \mathrm{vol} / \mathrm{vol}]$ ) at a flow rate $0.18 \mathrm{ml} / \mathrm{min}$. The run was programmed for $3 \mathrm{~min}$ of $100 \%$ solvent $\mathrm{A}$ and a linear increase to $25 \%$ solvent $\mathrm{B}$ in $18 \mathrm{~min}$, then to $100 \%$ solvent $\mathrm{B}$ in $2 \mathrm{~min}$, followed by isocratic postrun of $100 \%$ solvent A for $10 \mathrm{~min}$. Chiral phase HPLC (CHIRALCEL OD-H, $2.1 \times 150 \mathrm{~mm}$ ) (Diacel Chemical Industries) was also used to distinguish between enzymatic products and auto-oxidation products (Keereetaweep et al. 2013; Kilaru et al. 2011). An Agilent gas chromatography $7890 \mathrm{~A} / \mathrm{MSD} 5975 \mathrm{C}$ system with a capillary HP-5MS column $(30 \mathrm{~m} \times 0.250 \mathrm{~mm}, 0.25 \mathrm{~mm}$ coating thickness) (Agilent Technologies) was used to identify the trimethylsilyl derivatives of oxylipins in full mass scan mode. The oven temperature was programmed at $40^{\circ} \mathrm{C}$ for $1 \mathrm{~min}$, from 40 to $200^{\circ} \mathrm{C}$ at $50^{\circ} \mathrm{C} / \mathrm{min}$, from 200 to $285^{\circ} \mathrm{C}$ at $5^{\circ} \mathrm{C} / \mathrm{min}$, followed by $300^{\circ} \mathrm{C}$ for $15 \mathrm{~min}$. The flow rate was set at $0.5 \mathrm{ml} / \mathrm{min}$, using ultrapure helium as a carrier gas, and the transfer line was kept at $280^{\circ} \mathrm{C}$. Characteristic identification was based on molecular and fragment ions in comparison with commercial standards (Cayman Chemicals).

\section{Generation of RNAi wheat transgenics.}

To generate RNAi constructs for suppression of TaLpx-1, primers were developed for two regions in the lipoxygenase domain of TaLpx-1. The regions corresponded to 1,649 to 1,863 bp (WhLOX2) and 1,940 to 2,108 bp (LpxB1.1) on GQ166692. cDNA generated from total RNA isolated from 5day-old roots of $\mathrm{cv}$. Bobwhite served as the template. The
RT-PCR products so obtained were cloned in pANDA-Mini vectors for wheat transformation, which allows the cloning of the gene or PCR fragment of interest as inverted repeats that are separated by a GUS linker (Miki and Shimamoto 2004). The RNAi construct and the pAHC20 plasmid that contains the selectable Ubi:bar construct (Christensen and Quail 1996) were cobombarded into immature wheat embryos and transformed plants were regenerated using a previously described protocol (Altpeter et al. 1996) as modified by Anand and associates (2003). The bar gene, which confers resistance to the herbicide glufosinate (trade name Liberty; Bayer Crop Sciences), was used to select transgenic calli. Two independent RNAi transgenic lines, 1097B and 1073A, were obtained for the region named $L p x B 1.1$ and one RNAi transgenic line 1218A was obtained for the region named WhLOX2. Genomic PCR was used to monitor the presence of RNAi constructs using the forward primers for the respective regions and a GUS linker primer in the $T_{1}$ generation. In the $T_{2}$ and $T_{3}$ generations, RT-PCR analysis using insert-specific primers was used to determine gene suppression.

\section{ACKNOWLEDGMENTS}

We thank C. Castresana for making available the $L O X 1_{\mathrm{p}}$ :GUS and LOX $5_{\mathrm{p}}$ :GUS Arabidopsis lines, D. Maier and E. Kattan for assistance with experiments, and K. Chapman for gas chromatography-mass spectrometry. This work was supported by funding from the United States Department of Agriculture (agreement numbers 59-0200-3-003 and 59-0790-8-060) as cooperative projects with the U.S. Wheat \& Barley Scab Initiative to J. Shah and H. N. Trick and by the National Science Foundation (MCB-0920600) to J. Shah.

\section{LITERATURE CITED}

Altpeter, F., Vasil, V., Srivastava, V., Stöger, E., and Vasil, I. K. 1996. Accelerated production of transgenic wheat (Triticum aestivum L.) plants. Plant Cell Rep. 16:12-17.

Anand, A., Schmelz, E. A., and Muthukrishnan, S. 2003. Development of a lesion-mimic phenotype in a transgenic wheat line overexpressing genes for pathogenesis-related (PR) proteins is dependent on salicylic acid concentration. Mol. Plant-Microbe Interact. 16:916-925.

Bai, G., and Shaner, G. 2004. Management and resistance in wheat and barley to Fusarium head blight. Annu. Rev. Phytopathol. 42:135-161.

Bannenberg, G., Martínez, M., Hamberg, M., and Castresana, C. 2009 Diversity of the enzymatic activity in the lipoxygenase gene family of Arabidopsis thaliana. Lipids 44:85-95.

Blümke, A., Falter, C., Herrfurth, C., Sode, B., Bode, R., Schäfer, W., Feussner, I., and Voigt, C. A. 2014. Secreted fungal effector lipase releases free fatty acids to inhibit innate immunity-related callose formation during wheat head infection. Plant Physiol. 165:346-358.

Bohland, C., Balkenhohl, T., Loers, G., Feussner, I., and Grambow, H. J. 1997. Differential induction of lipoxygenase isoforms in wheat upon treatment with rust fungus elicitor, chitin oligosaccharides, chitosan, and methyl jasmonate. Plant Physiol. 114:679-685.

Brodhagen, M., and Keller, N. P. 2006. Signalling pathways connecting mycotoxin production and sporulation. Mol. Plant Pathol. 7:285-301.

Brown, N. A., Antoniw, J., and Hammond-Kosack, K. E. 2012. The predicted secretome of the plant pathogenic fungus Fusarium graminearum: A refined comparative analysis. PLoS ONE 7:e33731.

Brown, N. A., Urban, M., van de Meene, A. M., and Hammond-Kosack, K. E. 2010. The infection biology of Fusarium graminearum: Defining the pathways of spikelet to spikelet colonisation in wheat ears. Fungal Biol 114:555-571.

Browse, J. 2009. Jasmonate passes muster: A receptor and targets for the defense hormone. Annu. Rev. Plant Biol. 60:183-205.

Carrera, A., Echenique, V., Zhang, W., Helguera, M., Manthey, F., Schrager, A., Picca, A., Cervigni, G., and Dubcovsky, J. 2007. A deletion at the $L p x-B 1$ locus is associated with low lipoxygenase activity and improved pasta color in durum wheat (Triticum turgidum ssp. durum). J. Cereal Sci. 45:67-77.

Chen, X., Steed, A., Harden, C., and Nicholson, P. 2006. Characterization of Arabidopsis thaliana-Fusarium graminearum interactions and identification of variation in resistance among ecotypes. Mol. Plant Pathol. 7:391-403. 
Chen, X., Steed, A., Travella, S., Keller, B., and Nicholson, P. 2009 Fusarium graminearum exploits ethylene signalling to colonize dicotyledonous and monocotyledonous plants. New Phytol. 182:975-983.

Christensen, A. H., and Quail, P. H. 1996. Ubiquitin promoter-based vectors for high-level expression of selectable and/or screenable marker genes in monocotyledonous plants. Transgenic Res. 5:213-218.

Christensen, S. A., and Kolomiets, M. V. 2011. The lipid language of plantfungal interactions. Fungal Genet. Biol. 48:4-14.

Constantino, N. N., Mastouri, F., Damarwinasis, R., Borrego, E. J., MoranDiez, M. E., Kenerley, C. M., Gao, X., and Kolomiets, M. V. 2013. Rootexpressed maize lipoxygenase 3 negatively regulates induced systemic resistance to Colletotrichum graminicola in shoots. Front. Plant Sci. 4: 510.

Cuzick, A., Lee, S., Gezan, S., and Hammond-Kosack, K. E. 2008. NPR1 and EDS11 contribute to host resistance against Fusarium culmorum in Arabidopsis buds and flowers. Mol. Plant Pathol. 9:697-704.

Diethelm, M., Schmolke, M., Groth, J., Friedt, W., Schweizer, G., and Hartl, L. 2014. Association of allelic variation in two NPR1-like genes with Fusarium head blight resistance in wheat. Mol. Breed. 34:31-34.

Ding, L., Xu, H., Yi, H., Yang, L., Kong, Z., Zhang, L., Xue, S., Jia, H., and Ma, Z. 2011. Resistance to hemi-biotrophic F. graminearum infection is associated with coordinated and ordered expression of diverse defense signaling pathways. PLoS ONE 6:e19008.

Djamei, A., Schipper, K., Rabe, F., Ghosh, A., Vincon, V., Kahnt, J., Osorio, S., Tohge, T., Fernie, A. R., Feussner, I., Feussner, K., Meinicke, P., Stierhof, Y. D., Schwarz, H., Macek, B., Mann, M., and Kahmann, R. 2011. Metabolic priming by a secreted fungal effector. Nature 478: 395-398.

Doderer, A., Kokkelink, I., van der Veen, S., Valk, B.E., Schram, A. È. W., and Douma, A. C. 1992. Purification and characterization of two lipoxygenase isoenzymes from germinating barley. BBA-Protein Struct. M. 1120:97-104.

Feng, B., Dong, Z., Xu, Z., An, X., Qin, H., Wu, N., Wang, D., and Wang, T. 2010. Molecular analysis of lipoxygenase (LOX) genes in common wheat and phylogenetic investigation of LOX proteins from model and crop plants. J. Cereal Sci. 52:387-394.

Feussner, I., and Wasternack, C. 2002. The lipoxygenase pathway. Annu. Rev. Plant Biol. 53:275-297.

Gao, C. S., Kou, X. J., Li, H. P., Zhang, J. B., Saad, A. S. I., and Liao, Y. C. 2013. Inverse effects of Arabidopsis NPRI gene on fusarium seedling blight and fusarium head blight in transgenic wheat. Plant Pathol. 62: 383-392.

Gao, X., Brodhagen, M., Isakeit, T., Brown, S. H., Göbel, C., Betran, J., Feussner, I., Keller, N. P., and Kolomiets, M. V. 2009. Inactivation of the lipoxygenase $\mathrm{ZmLOX3}$ increases susceptibility of maize to Aspergillus spp. Mol. Plant-Microbe Interact. 22:222-231.

Gao, X., Shim, W.-B., Göbel, C., Kunze, S., Feussner, I., Meeley, R., BalintKurti, P., and Kolomiets, M. 2007. Disruption of a maize 9-lipoxygenase results in increased resistance to fungal pathogens and reduced levels of contamination with mycotoxin fumonisin. Mol. Plant-Microbe Interact. 20:922-933.

Gao, X., Starr, J., Göbel, C., Engelberth, J., Feussner, I., Tumlinson, J., and Kolomiets, M. 2008. Maize 9-lipoxygenase ZmLOX3 controls development, root-specific expression of defense genes, and resistance to rootknot nematodes. Mol. Plant-Microbe Interact. 21:98-109.

Göbel, C., Feussner, I., Schmidt, A., Scheel, D., Sanchez-Serrano, J., Hamberg, M., and Rosahl, S. 2001. Oxylipin profiling reveals the preferential stimulation of the 9-lipoxygenase pathway in elicitor-treated potato cells. J. Biol. Chem. 276:6267-6273.

Görlach, J., Volrath, S., Knauf-Beiter, G., Hengy, G., Beckhove, U., Kogel, K. H., Oostendorp, M., Staub, T., Ward, E., Kessmann, H., and Ryals, J. 1996. Benzothiadiazole, a novel class of inducers of systemic acquired resistance, activates gene expression and disease resistance in wheat. Plant Cell 8:629-643.

Goswami, R. S., and Kistler, H. C. 2004. Heading for disaster: Fusarium graminearum on cereal crops. Mol. Plant Pathol. 5:515-525

Han, S., and Kim, D. 2006. AtRTPrimer: Database for Arabidopsis genome-wide homogeneous and specific RT-PCR primer-pairs. BMC Bioinformatics 7:179.

Hart, G. E., and Langston, P. J. 1977. Chromosomal location and evolution of isozyme structural genes in hexaploid wheat. Heredity 39:263-277.

Hessler, T., Thomson, M., Benscher, D., Nachit, M., and Sorrells, M. 2002. Association of a lipoxygenase locus, $L p x-B 1$, with variation in lipoxygenase activity in durum wheat seeds. Crop Sci. 42:1695-1700.

Howe, G. A., and Jander, G. 2008. Plant immunity to insect herbivores. Annu. Rev. Plant Biol. 59:41-66

Huang, W. E., Huang, L., Preston, G. M., Naylor, M., Carr, J. P., Li, Y., Singer, A. C., Whiteley, A. S., and Wang, H. 2006. Quantitative in situ assay of salicylic acid in tobacco leaves using a genetically modified biosensor strain of Acinetobacter sp. ADP1. Plant J. 46:1073-1083.

Huang, W. E., Wang, H., Zheng, H., Huang, L., Singer, A. C., Thompson, I., and Whiteley, A. S. 2005. Chromosomally located gene fusions constructed in Acinetobacter sp. ADP1 for the detection of salicylate. Environ. Microbiol. 7:1339-1348.

Hwang, I. S., and Hwang, B. K. 2010. The pepper 9-lipoxygenase gene $C a L O X 1$ functions in defense and cell death responses to microbial pathogens. Plant Physiol. 152:948-967.

Isakeit, T., Gao, X., and Kolomiets, M. 2007. Increased resistance of a maize mutant lacking the 9-Lipoxygenase gene, zmlox3, to root rot caused by Exserohilum pedicellatum. J. Phytopathol. 155:758-760.

Johnson, D. D., Flaskerud, G. K., Taylor, R. D., and Satyanarayana, V. 2003. Quantifying economic impacts of Fusarium head blight in wheat American Phytopathological Society Press, St. Paul, MN.

Keereetaweep, J., Blancaflor, E. B., Hornung, E., Feussner, I., and Chapman, K. D. 2013. Ethanolamide oxylipins of linolenic acid can negatively regulate Arabidopsis seedling development. Plant Cell 25: 3824-3840.

Kilaru, A., Herrfurth, C., Keereetaweep, J., Hornung, E., Venables, B. J., Feussner, I., and Chapman, K. D. 2011. Lipoxygenase-mediated oxidation of polyunsaturated $\mathrm{N}$-acylethanolamines in Arabidopsis. J. Biol. Chem. 286:15205-15214.

Kruger, W. M., Pritsch, C., Chao, S., and Muehlbauer, G. J. 2002. Functional and comparative bioinformatic analysis of expressed genes from wheat spikes infected with Fusarium graminearum. Mol. PlantMicrobe Interact. 15:445-455.

Kunkel, B. N., and Brooks, D. M. 2002. Cross talk between signaling pathways in pathogen defense. Curr. Opin. Plant Biol. 5:325-331.

Li, G., and Yen, Y. 2008. Jasmonate and ethylene signaling pathway may mediate Fusarium head blight resistance in wheat. Crop Sci. 48: 1888-1896

Livak, K. J., and Schmittgen, T. D. 2001. Analysis of relative gene expression data using real-time quantitative PCR and the $2\left(-\Delta \Delta \mathrm{C}\left({ }_{\mathrm{T}}\right)\right)$ method. Methods 25:402-408.

López, M. A., Vicente, J., Kulasekaran, S., Vellosillo, T., Martínez, M., Irigoyen, M. L., Cascón, T., Bannenberg, G., Hamberg, M., and Castresana, C. 2011. Antagonistic role of 9-lipoxygenase-derived oxylipins and ethylene in the control of oxidative stress, lipid peroxidation and plant defence. Plant J. 67:447-458.

Makandar, R., Essig, J. S., Schapaugh, M. A., Trick, H. N., and Shah, J. 2006. Genetically engineered resistance to Fusarium head blight in wheat by expression of Arabidopsis NPR1. Mol. Plant-Microbe Interact. 19:123-129.

Makandar, R., Nalam, V., Chaturvedi, R., Jeannotte, R., Sparks, A. A., and Shah, J. 2010. Involvement of salicylate and jasmonate signaling pathways in Arabidopsis interaction with Fusarium graminearum. Mol. Plant-Microbe Interact. 23:861-870.

Makandar, R., Nalam, V. J., Chowdhury, Z., Sarowar, S., Klossner, G., Lee, H., and Burdan, D., Trick, H.N., Gobbato, E., Parker, J. and Shah, J. 2015 The combined action of ENHANCED DISEASE SUSCEPTIBILITY1, PHYTOALEXIN DEFICIENT4 and SENESCENCE-ASSOCIATED101 promotes salicylic acid-mediated defenses to limit Fusarium graminearum infection in Arabidopsis thaliana. Mol. Plant-Microbe Interact 8:943-953.

Makandar, R., Nalam, V. J., Lee, H., Trick, H. N., Dong, Y., and Shah, J. 2012. Salicylic acid regulates basal resistance to Fusarium head blight in wheat. Mol. Plant-Microbe Interact. 25:431-439.

Malamy, J. E., and Benfey, P. N. 1997. Organization and cell differentiation in lateral roots of Arabidopsis thaliana. Development 124:33-44.

Marmey, P., Jalloul, A., Alhamdia, M., Assigbetse, K., Cacas, J.-L., Voloudakis, A. E., Champion, A., Clerivet, A., Montillet, J.-L., and Nicole, M. 2007. The 9-lipoxygenase GhLOX1 gene is associated with the hypersensitive reaction of cotton Gossypium hirsutum to Xanthomonas campestris pv malvacearum. Plant Physiol. Biochem. 45:596-606.

Mauch, F., Kmecl, A., Schaffrath, U., Volrath, S., Görlach, J., Ward, E., Ryals, J., and Dudler, R. 1997. Mechanosensitive expression of a lipoxygenase gene in wheat. Plant Physiol. 114:1561-1566.

McMullen, M., Jones, R., and Gallenberg, D. 1997a. Scab of wheat and barley: A re-emerging disease of devastating impact. American Phytopathological Society. ETATS-UNIS, St. Paul, MN.

McMullen, M. P., Schatz, B., Stover, R., and Gregoire, T. 1997b. Studies of fungicide, application timing, and application technologies to reduce Fusarium head blight and deoxynivalenol. Cereal Res. Commun. 25 779-780.

Miki, D., and Shimamoto, K. 2004. Simple RNAi vectors for stable and transient suppression of gene function in rice. Plant Cell Physiol. 45: 490-495. 
Montillet, J.-L., Leonhardt, N., Mondy, S., Tranchimand, S., Rumeau, D., Boudsocq, M., Garcia, A. V., Douki, T., Bigeard, J., Laurière, C., Chevalier, A., Castresana, C., and Hirt, H. 2013. An abscisic acidindependent oxylipin pathway controls stomatal closure and immune defense in Arabidopsis. PLoS Biol. 11:e1001513.

Mosblech, A., Feussner, I., and Heilmann, I. 2009. Oxylipins: Structurally diverse metabolites from fatty acid oxidation. Plant Physiol. Biochem. 47:511-517.

Mur, L. A. J., Kenton, P., Atzorn, R., Miersch, O., and Wasternack, C. 2006. The outcomes of concentration-specific interactions between salicylate and jasmonate signaling include synergy, antagonism, and oxidative stress leading to cell death. Plant Physiol. 140:249-262.

Nalam, V. J., Keereetaweep, J., and Shah, J. 2013. The green peach aphid, Myzus persicae, acquires a LIPOXYGENASE5-derived oxylipin from Arabidopsis thaliana, which promotes colonization of the host plant. Plant signaling \& behavior 8:1 e22735.

Nalam, V. J., Keeretaweep, J., Sarowar, S., and Shah, J. 2012. Root-derived oxylipins promote green peach aphid performance on Arabidopsis foliage. Plant Cell 24:1643-1653.

Pieterse, C. M. J., Leon-Reyes, A., Van der Ent, S., and Van Wees, S. C. M. 2009. Networking by small-molecule hormones in plant immunity. Nat. Chem. Biol. 5:308-316.

Pirgozliev, S. R., Edwards, S. G., Hare, M. C., and Jenkinson, P. 2003. Strategies for the control of Fusarium head blight in cereals. Eur. J. Plant Pathol. 109:731-742.

Pritsch, C., Muehlbauer, G. J., Bushnell, W. R., Somers, D. A., and Vance, C. P. 2000. Fungal development and induction of defense response genes during early infection of wheat spikes by Fusarium graminearum. Mol. Plant-Microbe Interact. 13:159-169.

Ray, S., Anderson, J. M., Urmeev, F. I., and Goodwin, S. B. 2003. Rapid induction of a protein disulfide isomerase and defense-related genes in wheat in response to the hemibiotrophic fungal pathogen Mycosphaerella graminicola. Plant Mol. Biol. 53:741-754.

Rustérucci, C., Montillet, J.-L., Agnel, J.-P., Battesti, C., Alonso, B., Knoll, A., Bessoule, J.-J., Etienne, P., Suty, L., Blein, J.-P., and Triantaphylidès, C. 1999. Involvement of lipoxygenase-dependent production of fatty acid hydroperoxides in the development of the hypersensitive cell death induced by cryptogein on tobacco leaves. J. Biol. Chem. 274: 36446-36455

Sardesai, N., Subramanyam, S., Nemacheck, J., and Williams, C. E. 2005. Modulation of defense-response gene expression in wheat during Hessian fly larval feeding. J. Plant Interact. 1:39-50.

Savitch, L. V., Subramaniam, R., Allard, G. C., and Singh, J. 2007. The GLK1 'regulon' encodes disease defense related proteins and confers resistance to Fusarium graminearum in Arabidopsis. Biochem. Biophys. Res. Commun. 359:234-238.
Shah, J., Kachroo, P., and Klessig, D. F. 1999. The Arabidopsis ssi1 mutation restores pathogenesis-related gene expression in npr1 plants and renders defensin gene expression SA dependent. Plant Cell 11: 191-206.

Skadsen, R. W., and Hohn, T. M. 2004. Use of Fusarium graminearum transformed with $g f p$ to follow infection patterns in barley and Arabidopsis. Physiol. Mol. Plant Pathol. 64:45-53.

Urban, M., Daniels, S., Mott, E., and Hammond-Kosack, K. 2002. Arabidopsis is susceptible to the cereal ear blight fungal pathogens Fusarium graminearum and Fusarium culmorum. Plant J. 32:961-973.

Van Hemelrijck, W., Wouters, P. F. W., Brouwer, M., Windelinckx, A., Goderis, I. J. W. M., De Bolle, M. F. C., Thomma, B. P. H. J., Cammue, B. P. A., and Delauré, S. L. 2006. The Arabidopsis defense response mutant esa1 as a model to discover novel resistance traits against Fusarium diseases. Plant Sci. 171:585-595.

van Mechelen, J. R., Schuurink, R. C., Smits, M., Graner, A., Douma, A. C., Sedee, N. J. A., Schmitt, N. F., and Valk, B. E. 1999. Molecular characterization of two lipoxygenases from barley. Plant Mol. Biol. 39: 1283-1298.

Vellosillo, T., Martínez, M., López, M. A., Vicente, J., Cascón, T., Dolan, L., Hamberg, M., and Castresana, C. 2007. Oxylipins produced by the 9lipoxygenase pathway in Arabidopsis regulate lateral root development and defense responses through a specific signaling cascade. Plant Cell 19:831-846.

Vicente, J., Cascón, T., Vicedo, B., García-Agustín, P., Hamberg, M., and Castresana, C. 2012. Role of 9-lipoxygenase and $\alpha$-dioxygenase oxylipin pathways as modulators of local and systemic defense. Mol. Plant 5:914-928.

Voigt, C. A., Schäfer, W., and Salomon, S. 2005. A secreted lipase of Fusarium graminearum is a virulence factor required for infection of cereals. Plant J. 42:364-375.

Wilson, R. A., Gardner, H. W., and Keller, N. P. 2001. Cultivar-dependent expression of a maize lipoxygenase responsive to seed infesting fungi. Mol. Plant-Microbe Interact. 14:980-987.

Wu, J., and Baldwin, I. T. 2010. New insights into plant responses to the attack from insect herbivores. Annu. Rev. Genet. 44:1-24.

$\mathrm{Xu}, \mathrm{X}$., and Nicholson, P. 2009. Community ecology of fungal pathogens causing wheat head blight. Annu. Rev. Phytopathol. 47:83-103.

Yu, G. Y., and Muehlbauer, G. J. 2001. Benzothiadiazole-induced gene expression in wheat spikes does not provide resistance to Fusarium head blight. Physiol. Mol. Plant Pathol. 59:129-136.

\section{AUTHOR-RECOMMENDED INTERNET RESOURCE}

Dana-Farber Cancer Institute website: http://compbio.dfci.harvard.edu/ 